\title{
TOWARDS 3D MAPPING OF SEAGRASS MEADOWS WITH TOPO-BATHYMETRIC LIDAR FULL WAVEFORM PROCESSING
}

\author{
Mathilde Letard ${ }^{1}$, Antoine Collin ${ }^{1}$, Dimitri Lague ${ }^{2}$, Thomas Corpetti ${ }^{3}$, Yves Pastol ${ }^{4}$, Anders Ekelund , $^{5}$ \\ Gérard Pergent ${ }^{6}$, Stéphane Costa ${ }^{7}$
}

1. EPHE, PSL Université Paris, CNRS UMR 6554 LETG, Dinard, France.

2. Univ Rennes, CNRS, Géosciences Rennes - UMR 6118, Rennes, France

3. CNRS UMR 6554 LETG, Rennes, France.

4. SHOM, Brest, France.

5. AHAB, Leica Geosystems, Hexagon, Jönköping, Sweden.

6. FRES 3041 - UMR 6134, University of Corsica, Corte, France.

7. Université Caen-Normandie, CNRS UMR 6554 LETG, Caen, France.

\begin{abstract}
Topo-bathymetric lidar is a powerful tool to survey coastal ecosystems while ensuring data continuity between land and water regardless of the nature of the terrain, and allowing the collection of information up to several dozens of metres deep. This study analyzes the potential of full waveform lidar data to monitor key ecosystems for climate change mitigation: seagrasses. It proposes an original way of processing topo-bathymetric lidar waveforms to map their spatial repartition and extent in Corsica (France). Waveform statistical and shape parameters are computed and used to produce a map of seagrass meadows that reaches over $86 \%$ of overall accuracy. Seagrass height is also extracted, offering perspectives for structural complexity assessment and ecosystem services quantification.
\end{abstract}

Index Terms - Topo-bathymetric lidar, Lidar waveform, Seagrass, 3D mapping, Machine learning.

\section{INTRODUCTION}

Seagrasses grow in worldwide nearshore areas and occupy thousands of square kilometers [1]. Seagrass meadows provide food support and habitat to marine species and human communities, protect coastlines by ensuring wave attenuation and are critical blue carbon sinks: they are therefore of great ecological interest to many coastal areas [2]. Although their role in ocean-climate change mitigation is widely recognized, seagrasses are threatened: a third of the European seagrass area was lost between 1869 and 2016 [3] due to multiple anthropogenic and natural stressors [4].

Monitoring the extent, health and diversity of seagrass ecosystems is crucial to ensure efficient and sustainable management of coastal waters. Maps of seagrass meadows are currently made by processing observations acquired with various techniques [5], as for example satellites [5], [6], [7], airborne [7] or UAV [8] imagery. Bathymetry extracted from sonar [9], [10], [11] acquisitions or lidar surveys [12], [13] is also the base of many seagrass ecosystems maps. However, both passive imagery techniques and active sonar surveys have limitations: passive imagery is constrained by water turbidity [5], [14] while sonar is unusable in unsafe navigation areas. Collecting inaccessible information on seagrasses is therefore still necessary. There is also a strong need for mapping approaches that allow three-dimensional structural information on seagrasses.

The present study shows how topo-bathymetric lidar can be used to survey seagrass ecosystems and provide both twodimensional - a map of the extent - and three-dimensional structural complexity knowledge - information on their state. It features an original signal processing method that proves that not only bathymetry but also benthic return characteristics allow seagrass detection and 3D mapping. This method was assessed on the East coast of Corsica (France, Figure 1), where seagrasses play a key role in ecological equilibrium maintenance. It opens perspectives for the study of coastal ecosystems - topo-bathymetric lidar ensures data continuity between land and water - as well as possibilities to better understand seagrass structural complexity and ecology on extended areas, independently from the terrain's safety.

\section{TOPOBATHYMETRIC LIDAR OPERATING PRINCIPLE}

Lidar uses the backscatter of a laser pulse to collect data on encountered obstacles, resulting in a dense point cloud. Topo-bathymetric lidar emits laser pulses on two different wavelengths: green $(515 \mathrm{~nm})$ and infrared $(1064 \mathrm{~nm})$. While the infrared wavelength is fully reflected by water, the green wavelength penetrates the water column and allows sea floor 
measurement in low turbidity situations. Airborne topobathymetric lidar is therefore ideal to collect continuous data on coastal areas.

Analysis of full waveform lidar data shows that the shape of the reflected signal provides information on the type of objects encountered. In marine areas, the backscattered signals contain three main parts: the sea surface return (a peak), the water column return and the benthic return (sea floor, a peak). Since light diffusion is impacted by water, the backscattered intensity of the benthic echo depends on the water column. Here, we focus on the benthic return's shape and statistical parameters and their use for seagrass detection and mapping.

\section{MATERIAL AND METHOD}

\subsection{Study area}

The study area is a $0.15 \mathrm{~km}^{2}$ nearshore zone located near San Giuliano in Corsica, France. Seagrasses - Posidonia oceanica and Cymodocea nodosa - occupy around 42000 ha of the East Coast of Corsica [15]. The selected area encompasses experimental shallow coastal waters including a part of the large $P$. oceanica meadow known as NATURA 2000 site "Grand herbier de la côte Orientale » and two small patches of $P$. oceanica surrounded by fine sediments. Depth ranges from 2 to 16.5 metres in this area.

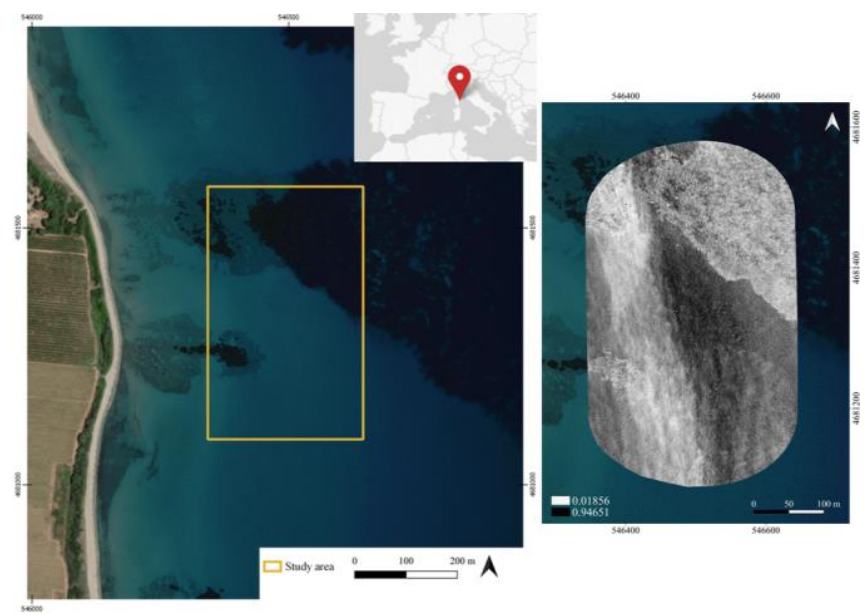

Figure 1. Location of the study area (WGS84 UTM32 N).

\subsection{Data used}

Topo-bathymetric lidar data acquired in October 2017 with a Leica HawkEye III system was used to conduct this study. The average point density across the zone is 0.99 point $/ \mathrm{m}^{2}$. Both the points and the full waveforms were used.

\subsection{Data processing method}

\subsubsection{Signal processing}

The waveforms (Figure 2) - i.e. the backscattered intensity signal - were first smoothed using a Savitzky Golay filter whose principle is to estimate piecewise polynomial functions to remove noise. The detection of benthic habitats implied to detect the peaks of the waveforms corresponding to the sea surface and to the sea floor. This was made by applying a threshold to the first derivative of the smoothed waveform. A two-step thresholding was adopted to detect both major and smaller peaks and avoid loss of information.

In order to remove the light attenuation component on the benthic echo, a decreasing exponential function is fitted to the water column component of the signal.

To remotely sense benthic habitats with these data, we converted the intensities into pseudo-reflectance values, dividing them by the intensity of the emitted laser pulse.

Various statistical parameters were then computed for each waveform, including benthic peak complexity, which was defined as the number of sign changes of the benthic return's first derivative. Four of these parameters describe the shape of the benthic return: skewness, kurtosis, time range and complexity. Eight other ones give statistics on the intensity variations of the benthic return: mean, median, maximum, variance, standard deviation, area under curve and amplitude. Topography information was also extracted: a bathymetry map, a digital surface model (including the vegetation above the seabed) and the height difference between them were computed. Finally, the pseudoattenuation, the benthic return's maximum before signal attenuation correction and the sea floor return's maximum before correction were computed.

\subsubsection{Image processing}

The parameters extracted from the topo-bathymetric lidar waveforms were rasterized by linearly interpolating the values on a $1.5 \mathrm{~m}$ resolved grid and stacked together to create a 17-band raster.

\subsubsection{Machine learning classification}

To generate a map of the extent of seagrasses from the waveforms' parameters, we performed a supervised image classification with a maximum likelihood probabilistic algorithm. The algorithm was trained by 8400 pixels collected on seagrass and sediment areas on the stacked bands, with the help of terrain knowledge provided by aerial imagery. The same number of 8400 pixels were also selected for results' validation.

The whole set of bands was first classified into two classes: sediment and seagrass. Then, we evaluated the contribution of each attribute by computing the accuracy difference between a classification in which it was used and another in which it was not. The parameters that lowered the accuracy were removed from the set of bands systematically, 
until the combination giving the best classification was found.

A contribution index of each band of the selected set was computed by dividing the accuracy difference between the classifications with and without the given attribute by the accuracy of the classification obtained with the whole set.

\section{RESULTS}

\subsection{Lidar waveform processing}

Figure 2 shows typical detection results for sediment and seagrass, and the output of the light attenuation correction.
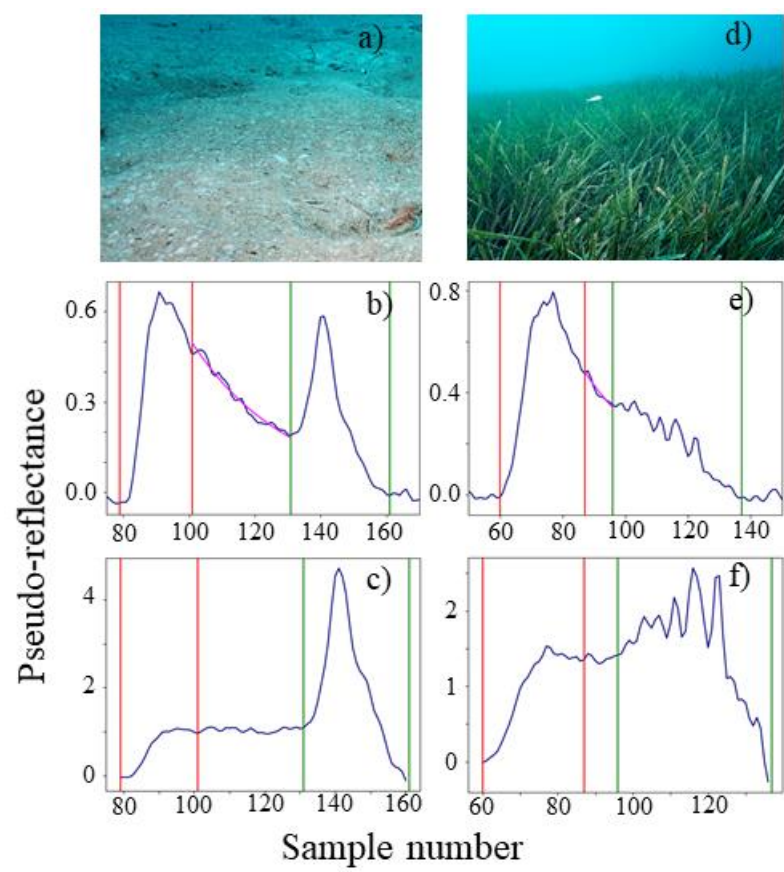

Figure 2. Extracts from the lidar dataset. a) sediment, b) uncorrected waveform, c) corrected waveform; d) seagrass, e) uncorrected waveform, f) corrected waveform. Red lines delimitate the sea surface return, green lines the benthic return; the pink curve is the fitted exponential.

\subsection{Machine learning waveform statistics classification}

The most efficient attributes' combination is formed by nine parameters: benthic return maximum before pseudoattenuation correction, peak skewness, pseudo-attenuation index, bathymetry, peak complexity, peak intensity variance, peak median intensity, peak time range.

Calibration pixels have a separability score (JeffriesMatusita distance) of 1.64 on these bands.

The maximum likelihood classification of the eight most accurate attributes reaches $86.4 \%$ of global accuracy and a Kappa coefficient of 0.73 . The height difference between the DEM and DSM computed give an overview of seagrass height in the meadow areas. These are presented in Figure 3.

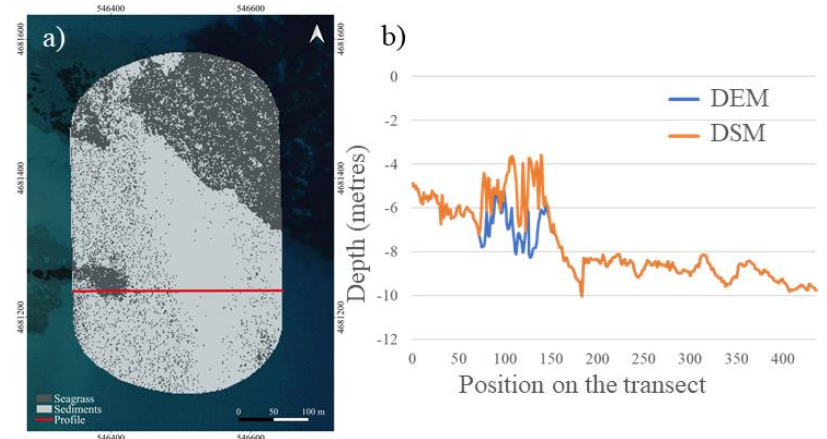

Figure 3. a) map of seabed types in the study area, b) topof-vegetation and seabed depth profile (metres).

The contribution of each parameter of the selected set is presented in Figure 4. Contributions are sorted in descending order and range from 0.43 to 5.01 percent.

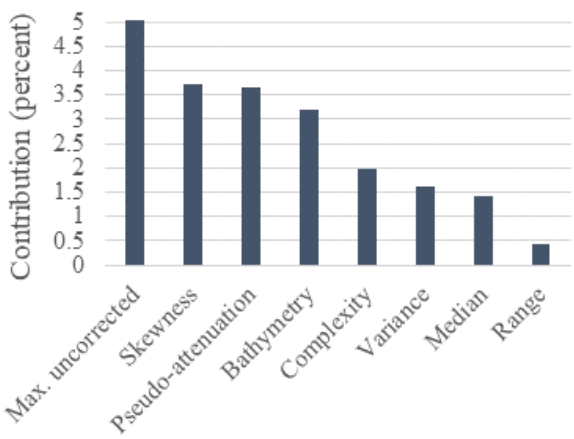

Figure 4: Contribution of the selected attributes to the global accuracy of the best classification (in percent).

\section{DISCUSSION AND CONCLUSION}

The method used to remove the light attenuation component efficiently corrects the effects of a sediment plume on the reflected intensities. It confirms the usefulness of full waveform data in moderately turbid waters, when intensity alone is not enough to detect bottom variations. However, the correction is perfectible: the exponential over-corrects the attenuation, resulting in very high reflectance measurements. This weakness explains the apparition of pseudo-attenuation as one of the main predictors and the absence of the corrected intensity in the selected attributes.

The analysis of the extracted parameters and their contribution to classification accuracy shows that the returned signal's shape and intensity as well as the bathymetry are all relevant to precisely describe the seascape and its habitats. Results also underpin that the benthic return's shape is determined by the nature of the sea floor and that waveform analysis is still underexploited.

The seabed map obtained reaches $86 \%$ of global accuracy and shows both seagrass patches and seagrass extended meadows. Some parts of the site are however misclassified: in very dense vegetation areas, the signal seems unable to penetrate the canopy and the echo has the 
same shape as a bare ground echo, explaining the relatively low accuracy obtained. A correction that does not exponentially increase the intensity could compensate these effects, since the maximum of the benthic return has the potential to be more discriminant if well corrected.

Lidar avoids technical limitations encountered by satellite or aerial images-based approaches [5], [14], [9] and is therefore efficient to monitor coastal ecosystems [12], including seagrasses, which usually require landscapespecific mapping approaches to avoid mis-estimation of their extent due to their complex spatial organization [10]. It also offers the possibility to extract seagrass height (Figure 3), which provides insightful elements for seascape analysis and structural ecology assessment of seagrasses. This height estimation could however be improved by interpolating bathymetry under seagrass areas, since the vegetation absorbs all the signal at some point, preventing the extraction of a real bottom echo and biasing the bathymetry and the derived vegetation height.

The waveform decomposition [16], slope correction [13], use of bathymetry-derived parameters [12] or deep learning classification [17] might besides improve sea floor detection and 3D mapping. Although ground truth validation is expected to refine these results, our work already opens various perspectives for coastal habitats monitoring. Further investigation of full waveform data could allow seagrass species, phenological phase or health assessment and provide knowledge on their spatial dynamics depending on ocean currents, which can be studied with the same data.

\section{AKNOWLEDGEMENTS}

The authors would like to thank the Saur Group and the Région Bretagne for their support.

\section{REFERENCES}

[1] L.J. McKenzie, L.M. Nordlund, B.L. Jones, L.C. CullenUnsworth et al., "The global distribution of seagrass meadows", Environmental Research Letters 15, 2020.

[2] E.B. Barbier, S.D. Hacker, C. Kennedy, E.W. Koch, A.C. Stier and C.R. Silliman, "The value of estuarine and coastal ecosystem services”, Ecological Monographs 81, pp. 169-193, 2011.

[3] C. B. De los Santos, D. Krause-Jensen, T. Alcoverro, N. Marbà, C. M. Duarte et al., "Recent trend reversal for declining European seagrass meadows", Nature Communications 10, 2019.

[4] R.J. Orth, T.JB. Carruthers, W.C. Dennison, C.M. Duarte, J.W. Fourqurean et al, "A global crisis for Seagrass Ecosystems", BioScience 56, pp. 987-996, 2006.

[5] L.J. McKenzie, M.A. Finkbeiner, H. Kirkman, Global Seagrass Research Methods, Elsevier Science, 2001.
[6] K. Topouzelis, D. Makri, N. Stoupas, A. Papakonstantinou and S. Katsanevakis, "Seagrass mapping in Greek territorial waters using Landsat-8 satellite images", International Journal of Applied Earth Observation and Geoinformation 67, pp.98-113, 2018.

[7] P.J. Mumby, E.P. Green, A.J. Edwards, and C.D. Clark, "Measurement of seagrass standing crop using satellite and digital airborne remote sensing", Marine Ecology Progress Series 159, pp. 51-60, 1997.

[8] D. James, A. Collin, T. Houet, A. Mury, H. Gloria, and N. Le Poulain, "Towards Better Mapping of Seagrass Meadows using UAV Multispectral and Topographic Data," Journal of Coastal Research 95, pp.1117-1121, 2020.

[9] J. Barrell, J. Grant, A. Hanson and M. Mahoney, "Evaluating the complementarity of acoustic and satellite remote sensing for seagrass landscape mapping", International Journal of Remote Sensing 36, pp. 4069-4094, 2015.

[10] V. Pasqualini, C. Pergent-Martini, P. Clabaut and G. Pergent, "Mapping of Posidonia oceanica using aerial photographs and side scan sonar: application off the island of Corsica (France)", Estuarine, Coastal and Shelf Science 47, pp. 359-367, 1998.

[11] T. Komatsu, C. Igarashi, K. Tatsukawa, S. Sultana, Y. Matsuoka and S. Harada, "Use of multi-beam sonar to map seagrass beds in Otsuchi Bay on the Sanriku Coast of Japan", Aquatic Living Resources 16, pp. 223-230, 2003.

[12] R. Zavalas, D. Ierodiaconou, D. Ryan, A. Rattray and J. Monk, "Habitat classification of temperate marine macroalgal communities using bathymetric LiDAR", Remote sensing 6, pp. 2154-2175, 2014.

[13] C.K. Wang and W.D. Philpot, "Using airborne bathymetric LiDAR to detect bottom type variation in shallow waters", Remote sensing of Environment 106, pp. 123-135, 2007.

[14] T. Kutser, E. Vahtmäe and G. Martin, “Assessing suitability of multispectral satellites for mapping benthic macroalgal cover in turbid coastal waters by means of model simulations", Estuarine, Coastal and Shelf Science 67, pp. 521-529, 2006.

[15] A. Valette-Sansevin, G. Pergent, K. Buron, E. Damier and C. Pergent-Martini, "Continuous mapping of benthic habitats along the coast of Corsica: a tool for the inventory and monitoring of blue carbon ecosystems", Mediterranean Marine Science 20, pp. 585-593, 2019.

[16] Y. Qin, T.T. Vu, and Y. Ban, "Toward and optimal algorithm for LiDAR waveform decomposition”, IEEE Geoscience and Remote Sensing Letters 9, pp. 482-486, 2012.

[17] M. Letard, A. Collin, and Y. Pastol, "Improving mangrove and salt marsh mapping using superpixel-based deep classification of VHR superspectral satellite imagery and topobathymetric LiDAR data”, Sea Tech Week 2020 (12th edition), Brest, 2020. 